\title{
Theoretical studies of novel aromatic molecules and transition states*
}

\author{
Maja Nendel, Bernd Goldfuss, Brett Beno and K. N. Houkt, \\ K. Hafner ${ }^{1}$ and Hans-Jörg Lindner ${ }^{1}$
}

Department of Chemistry and Biochemistry, University of California, Los Angeles, 405 Hilgard Ave., Los Angeles, CA 90095-1569 USA; ${ }^{1}$ Institut für Organische Chemie der Technisch Universität Darmstadt, Petersenstrasse 22, D-6100 Darmstadt, Germany

\begin{abstract}
Monocyclic conjugated molecules have stabilities, bond lengths, and magnetic properties following expectations from Hückel's Rule. Two hydrocarbons which seem to deviate from these generalizations, $s$-indacene and cyclohepta[def]fluorene, were studied with density functional theory. The former has characteristics expected for both aromatic and antiaromatic molecules; the latter is a ground state triplet. Potentially aromatic transition states with 10 electrons were also investigated. The mechanism of the 5,5-sigmatropic shift is predicted to be stepwise involving diradical intermediates.
\end{abstract}

On the occasion of this splendid ISNA-9, it is my distinct pleasure and opportunity to summarize recent work on the electronic structures of novel aromatic systems, including our assessment of the nature of the transition states of pericyclic reactions involving 10 electrons. This presentation is divided into three parts: (i) a summary of our work $[1,2]$ on the computational methods to obtain geometries and properties of aromatic and nonaromatic systems; (ii) a description of our new results [3,4] on density functional theory studies of several novel $\pi$-systems which deviate from normal properties in several ways; and (iii) a summary of our studies of transition states of 5,5-sigmatropic shifts where we found that the aromatic concerted transition states which are common in six-electron pericyclic reactions are less favored than stepwise pathways involving diradical intermediates [5].

Of the many criteria for aromaticity proposed during this century, three have proven to be the most characteristic measures of aromaticity: energy, geometry, and magnetic properties. There is no necessary relationship between the three. Kinetic stability is a function of the energies of transition states for reactions, and thermodynamic stability depends upon the reference molecules. Bond lengths usually alternate between single and double for nonaromatic or antiaromatic systems, while aromatic systems have nearly equal bond lengths. Magnetic properties arise from the diamagnetic ring currents of aromatic systems.

Schleyer and coworkers showed that there are very good linear correlations between geometric, energetic, and magnetic properties of five-membered ring heterocycles [6]. For an extensive set of these heterocycles, the various criteria are in good agreement, providing a particularly straightforward interpretation of the electronic structures and properties of these molecules.

We have found that density functional theory, with the B3LYP functional and a relatively modest basis set $\left(6-31 \mathrm{G}^{*}\right)$ provides very good geometries and properties of the bridged-[14]annulenes [1,2]. For other aromatic systems, similar conclusions have been made by other researchers [6,7]. We have now applied density functional theory to study two very interesting unsaturated hydrocarbons, which we will show to deviate substantially from expectations based on monocyclic systems.

The tricyclic hydrocarbon, $s$-indacene, $\mathbf{1}$, is a $12 \pi$ electron system. Although this electron count would lead to the expectation of antiaromaticity, it has geometrical features normally associated with aromatic

*Lecture presented at the 9th International Symposium on Novel Aromatic Compounds (ISNA-9), Hong Kong,

China, 2-7 August 1998, pp. 209-302.

$\dagger$ Corresponding author: E-mail: houk@chem.ucla.edu 
systems. The parent is highly reactive and has not been characterized [1a], but 1,3,5,7-tetra-tert-butyl-sindacene was synthesized by K. Hafner's group in Darmstadt in the early 1980s. It is stable in the solid state, but decomposes in solution [8]. The X-ray structure has been obtained at room temperature [8] and later at $100 \mathrm{~K}$ [9]. The data are consistent with a $D_{2 \mathrm{~h}}$ symmetric structure; all double bonds are delocalized, varying only from 1.39 to $1.44 \AA$ (Fig. 1).

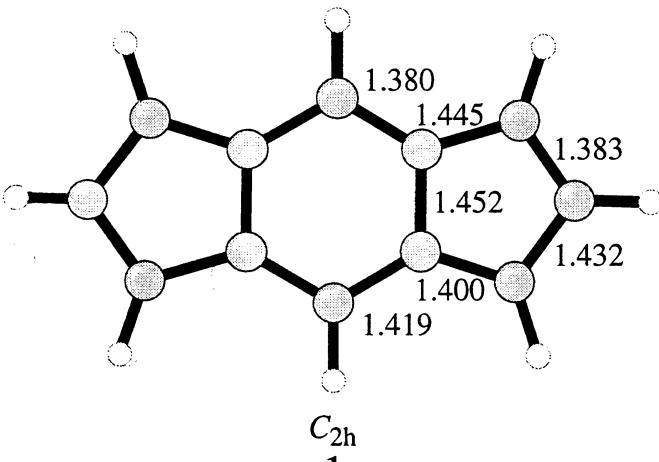

1

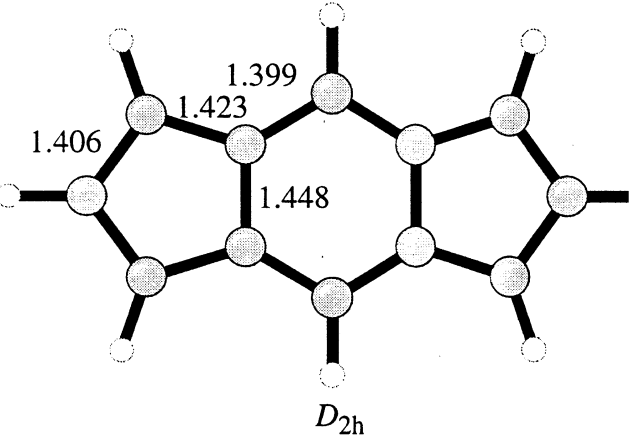

2

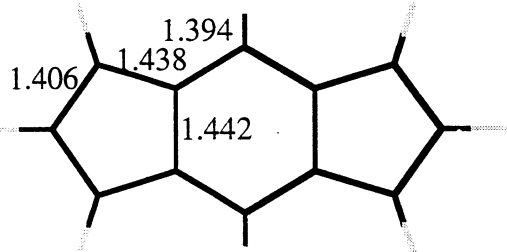

Fig. 1 B3LYP/6-31G* structures of s-indacene. The bond lengths from the X-ray structure of the tetra-tert-butyl derivative are shown below.

Numerous theoretical studies have been performed [10], but none provide a simple explanation of the $\mathrm{X}$-ray structure. Perturbation theory arguments which were generally successful in rationalizing geometries of polycyclic aromatics predicted bond alternation for the parent and substituted $s$-indacenes, in contradiction to the experimental results. MP2 calculations predicted a bond-localized structure, $\mathbf{1}$, to be $0.7 \mathrm{kcal} / \mathrm{mol}$ more stable than the delocalized 2, CASSCF single point calculations on the MP2 geometries increase this gap to $5.7 \mathrm{kcal} / \mathrm{mol}$, while CASPT2 single point calculations favor the delocalized structure over the localized one by $3.1 \mathrm{kcal} / \mathrm{mol}$. BLYP predicts a localized structure [10b] (Scheme 1).<smiles>C1=Cc2cc3c(cc2=C1)C=CC=3</smiles><smiles>C1=Cc2cc3c(cc2=C1)C=CC=3</smiles>

\section{Scheme 1}

B3LYP density functional calculations with the 6-31G* basis set using Gaussian 94 [13] gave two structures for $s$-indacene (Fig. 1). The $C_{2 \mathrm{~h}}$ symmetric structure, $\mathbf{1}$, is a minimum on the B3LYP/6-31G* surface, while the $D_{2 \mathrm{~h}}$ structure, $\mathbf{2}$, is a transition state for double bond isomerization. The imaginary frequency is $349 \mathrm{~cm}^{-1}$, and the transition vector connects $\mathbf{1 - 2}$. The delocalized $D_{2 \mathrm{~h}}$ structure, $\mathbf{2}$, is only $0.1 \mathrm{kcal} / \mathrm{mol}$ above the minimum. However, if the zero point energy is included, the transition state, $\mathbf{2}$, becomes $0.6 \mathrm{kcal} / \mathrm{mol}$ more stable than 1 (Scheme 2). The $D_{2 \mathrm{~h}}$ transition structure, 2 , is therefore the enthalpic energy minimum. The geometry of $\mathbf{2}$ also reproduces quite well the X-ray results on the tetratert-butyl derivative. We thus refer to this as a 'quasi-delocalized' molecule [3]. Both $\mathbf{1}$ and $\mathbf{2}$ have quite similar geometries with minimal bond-alternation. By the geometric criterion, either is aromatic! To further understand this surprising phenomenon, we explored other aromaticity criteria of $s$-indacene.

For quantitation of the three common aromaticity criteria, the following measures are used: (i) Geometric: bond alternation can be quantified by the Julg parameter $\mathrm{A}=1-(225 / n) \Sigma\left[1-\left(\mathrm{r}_{\mathrm{i}} / \mathrm{r}\right)\right]^{2}$, where $n$ 


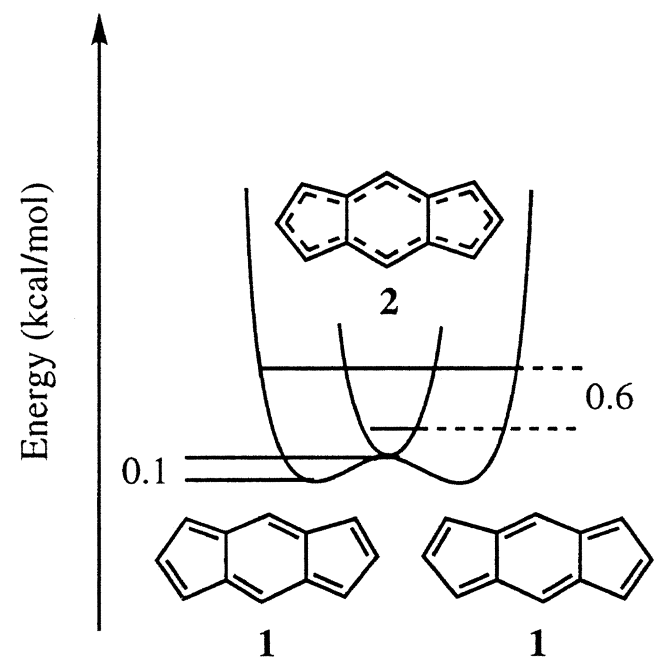

\section{Scheme 2}

is the number of delocalized $\mathrm{C}-\mathrm{C}$ bonds in the system, $\mathrm{r}_{\mathrm{i}}$ the length of an individual $\mathrm{C}-\mathrm{C}$ bond, and $\mathrm{r}$ is the mean $\mathrm{C}-\mathrm{C}$ bond length [11], or by $\Delta \mathrm{r}_{\mathrm{m}}$, which is the maximum deviation of the $\mathrm{C}-\mathrm{C}$ bond length from the mean $[1,2]$. For aromatic molecules, $\Delta \mathrm{r}_{\mathrm{m}}$ is generally less than $0.06 \AA$, while nonaromatics have larger $\Delta r_{\mathrm{m}}$. (ii) Energetic: aromatic stabilization energy (ASE) is used to assess the degree of stabilization. (iii) Magnetic: the nucleus independent chemical shift (NICS) is a simple aromaticity probe when the chemical shift at the center of the ring is calculated [12]. The exaltation of magnetic susceptibility over that expected for nonaromatic molecules is an alternative measure of aromaticity that can be measured or calculated [6].

The ASE values for $\mathbf{1}$ and anthracene were assessed by the homodesmotic equations given in Scheme 3. Although $s$-indacene has a $12 \pi$ electron system, $\mathbf{1}$ is stabilized by $10.8 \mathrm{kcal} / \mathrm{mol}$. This value is rather small, however, as compared to that of anthracene, which has an ASE of $61.8 \mathrm{kcal} / \mathrm{mol}$. The ASE of $s$-indacene is only about one-half that of benzene. By this criterion, $s$-indacene is nonaromatic.

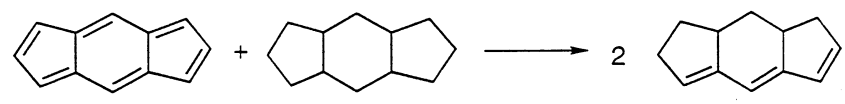<smiles>c1ccc2cc3ccccc3cc2c1</smiles><smiles>[C+]1=CCC2CC3CCCCC3CC2C1</smiles>
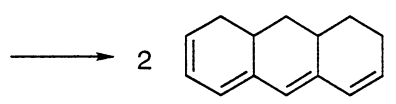

\section{Scheme 3}

The NICS values of the $D_{2 \mathrm{~h}}$ structure, 2 , are +25.8 and +20.8 , for the five- and six-membered rings, respectively. These compare to a NICS value of +28.8 for cyclobutadiene. The magnetic properties of $s$-indacene are consistent with an antiaromatic species (Scheme 4).

The linear relationships that exist between the different criteria for monocyclic systems [6] breaks down with $s$-indacene. The explanation for the 'aromatic geometry' can be found by comparison of the molecular orbitals of $s$-indacene to those of a planar all-cis [12] annulene. Cyclic $4 n \pi$ electron systems have degenerate nonbonding MOs. For $D_{12 \mathrm{~h}}$ [12]annulene, two such representations are shown in Fig. 2. Any other linear combination is also an acceptable representation. The monocyclic system will undergo a Jahn-Teller distortion to break this degeneracy, and two electrons will go into the more stable bonding orbital produced upon this distortion. For a monocycle, this distortion results in bond length alternation. This stabilizes orbital 3A and destabilizes 3B. B3LYP calculations predict that the $D_{12 \mathrm{~h}}[12]$ annulene is stabilized by about $12 \mathrm{kcal} / \mathrm{mol}$ by bond length alternation to form the $D_{6 \mathrm{~h}}$ structure. 


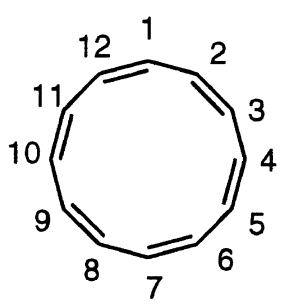

D6h

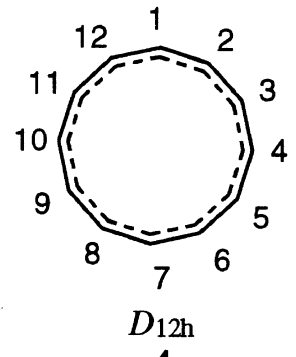

4

\section{Scheme 4}

In order to form the $\pi$ orbitals of $s$-indacene from the [12] annulene orbitals, bonding interactions are formed between $\mathrm{C} 2$ and $\mathrm{C} 6$ and between $\mathrm{C} 9$ and $\mathrm{C} 12$. Using the degenerate orbital set, $\mathbf{4 A} / \mathbf{4 B}$, one bonding orbital is formed from this union and becomes the doubly occupied HOMO. The other orbital remains nonbonding and becomes the LUMO. These bonding interactions stabilize the system. Because the uniting coefficients are larger in $\mathbf{4 A / 4 B}$, the interaction is larger when this set is used than for the bond alternation which can occur with the $\mathbf{3 A} / \mathbf{3 B}$ set. It is therefore advantageous for $s$-indacene to be delocalized and to have nodal planes on alternating carbon atoms in the HOMO. Stabilization of this antiaromatic system gives a nonaromatic system. The HOMO-LUMO gap is still quite small, however, which leads to a paramagnetic ring current and the corresponding NICS values.

Bis-periazulene presents another surprising type of potentially aromatic molecule which we have recently studied [4]. In 1965, Heilbronner predicted on the basis of PPP calculations that bis-periazulene, 5 (cyclohepta[def]fluorene), would have a triplet ground state [14]. Surprisingly, the structure with the aromatic $14 \pi$ periphery and an ethylene center, $\mathbf{5 a}$, is expected on this basis to be less stable than the diradical structure, $\mathbf{5 b}$. Many attempts at synthesis have been unsuccessful, even when the precursors contain substituents which are likely to stabilize the triplet diradical [15].

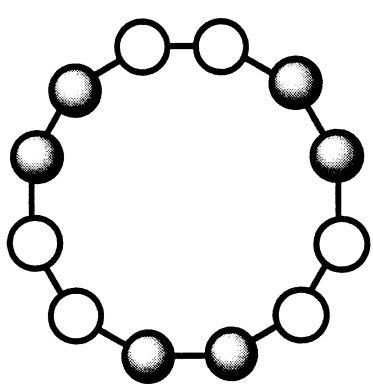

3A

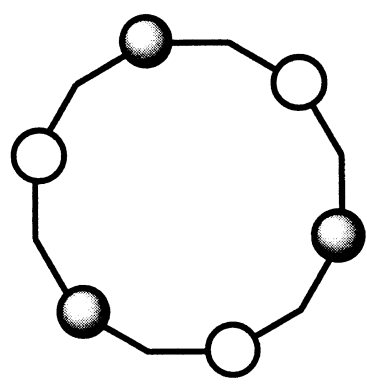

4A

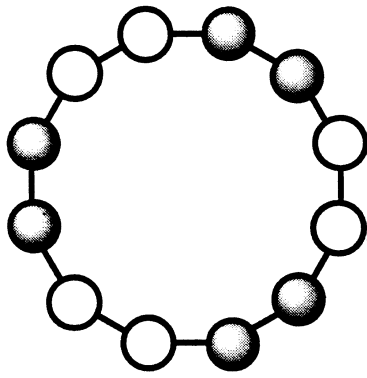

3B

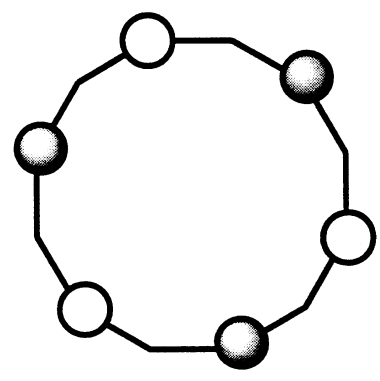

4B

Fig. 2 Two representations of the [12] annulene NBMOs. 
B3LYP/6-31G* calculations provide excellent singlet-triplet gaps for unsaturated hydrocarbons [16]. Such calculations predict that $\mathbf{5}$ has a triplet ground state, the structure of which is best represented as $\mathbf{5 b}$. The lowest singlet state is only $2 \mathrm{kcal} / \mathrm{mol}$ higher and is well-represented by structure $\mathbf{5 a}$. The optimized geometries are shown in Fig. 3 (Scheme 5).

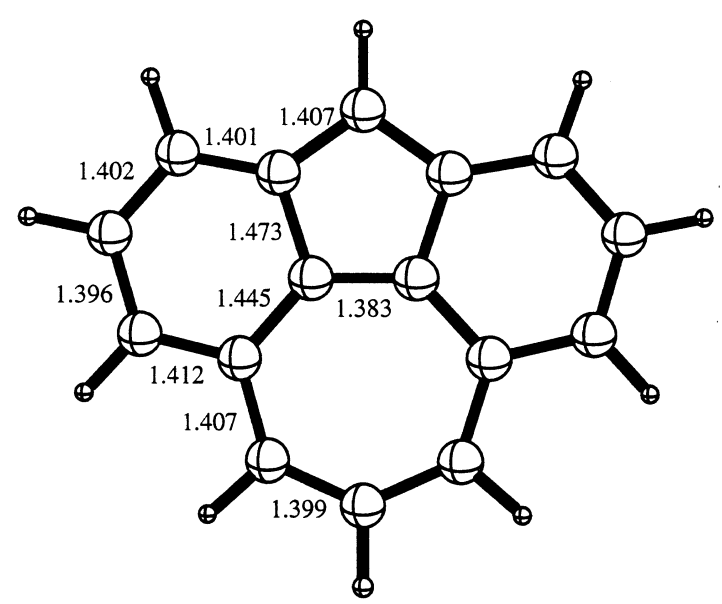

Singlet

$\mathrm{E}_{\mathrm{rel}}=2.3 \mathrm{kcal} / \mathrm{mol}$

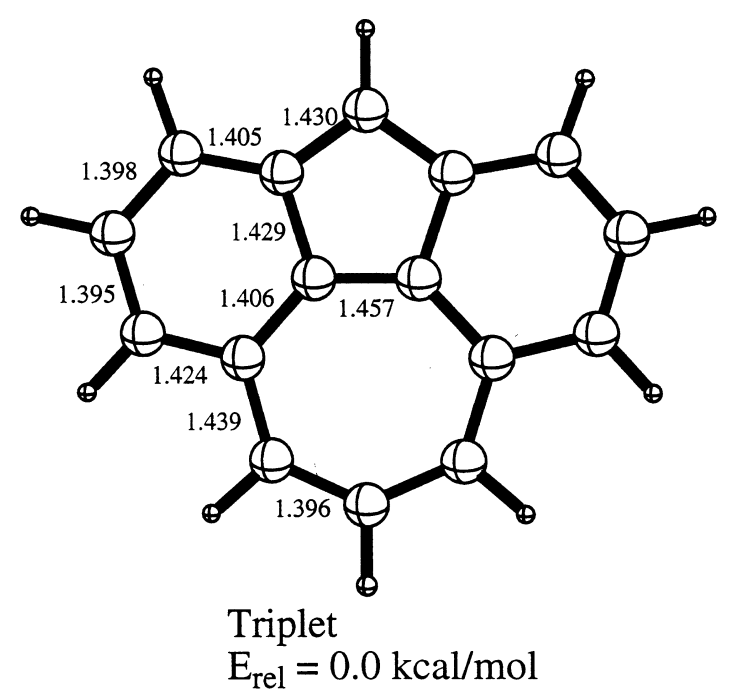

Fig. 3 Singlet and triplet B3LYP/6-31G* optimized bis-periazulene. The singlet is obtained from restricted or unrestricted calculations, while the triplet state is obtained by unrestricted calculations. Relative energies include ZPE.<smiles>c1cc2cccc3cc4cccc(c1)c2=c34</smiles>

5<smiles></smiles>

$5 a$

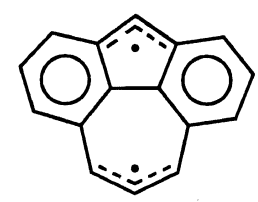

5b

Scheme 5 
The triplet ground state can be viewed as a biphenyl unit with two benzene rings $(r=1.395-1.429 \AA$ ) connected by a longer bond $(1.457 \AA)$. The optimized singlet has a geometry best described as the expected $14 \pi$ aromatic periphery $(r=1.396-1.407 \AA)$ joined to the central distorted ethylene $(r=1.383 \AA$ ) by relatively long bonds $(r=1.45-1.47 \AA)$. This structure is $2.3 \mathrm{kcal} / \mathrm{mol}$ above the triplet with ZPE corrections.

We have compared bis-periazulene to the isomeric pyrene, which contains only six-membered rings. The structures and NICS values are shown in Fig. 4. The lowest electronic state of pyrene is a singlet, and the lowest-lying triplet is predicted to be $45.8 \mathrm{kcal} / \mathrm{mol}$ (with ZPE) higher in energy. The singlet of pyrene has significant similarities to the triplet of bis-periazulene, in that pyrene has a biphenyl unit linked by two double bonds which are quite short.
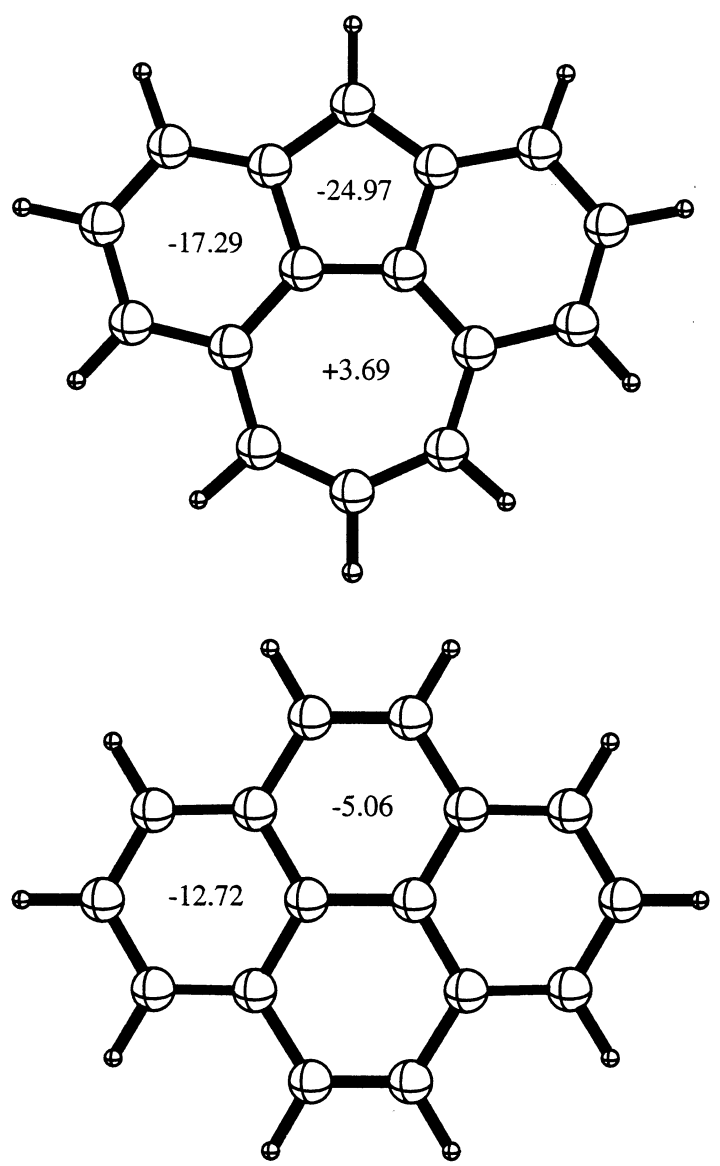

Fig. 4 The NICS values for bis-periazulene and for pyrene.

Finally, we have computed the structure of the $14 \pi$ electron monocycles produced by hydrogenation of the central bonds. Hydrogenation of bis-periazulene is $46.0 \mathrm{kcal} / \mathrm{mol}$ easier than hydrogenation of the central bond of pyrene. The difference in these values provides evidence for the high energy of bis-periazulene, partly due to angle strain, but also due to the difference in energy between two ethylene units in pyrene vs. the methyl plus allyl radical units of triplet bis-periazulene. The latter is worth $50 \mathrm{kcal} / \mathrm{mol}$.

Other properties of bis-periazulene are reported in our further account of this work [4].

The final subject of my lecture deals with the aromaticity — or lack thereof-in the transition states of some pericyclic reactions. Zimmerman and Dewar pointed out that the concerted transition states of 

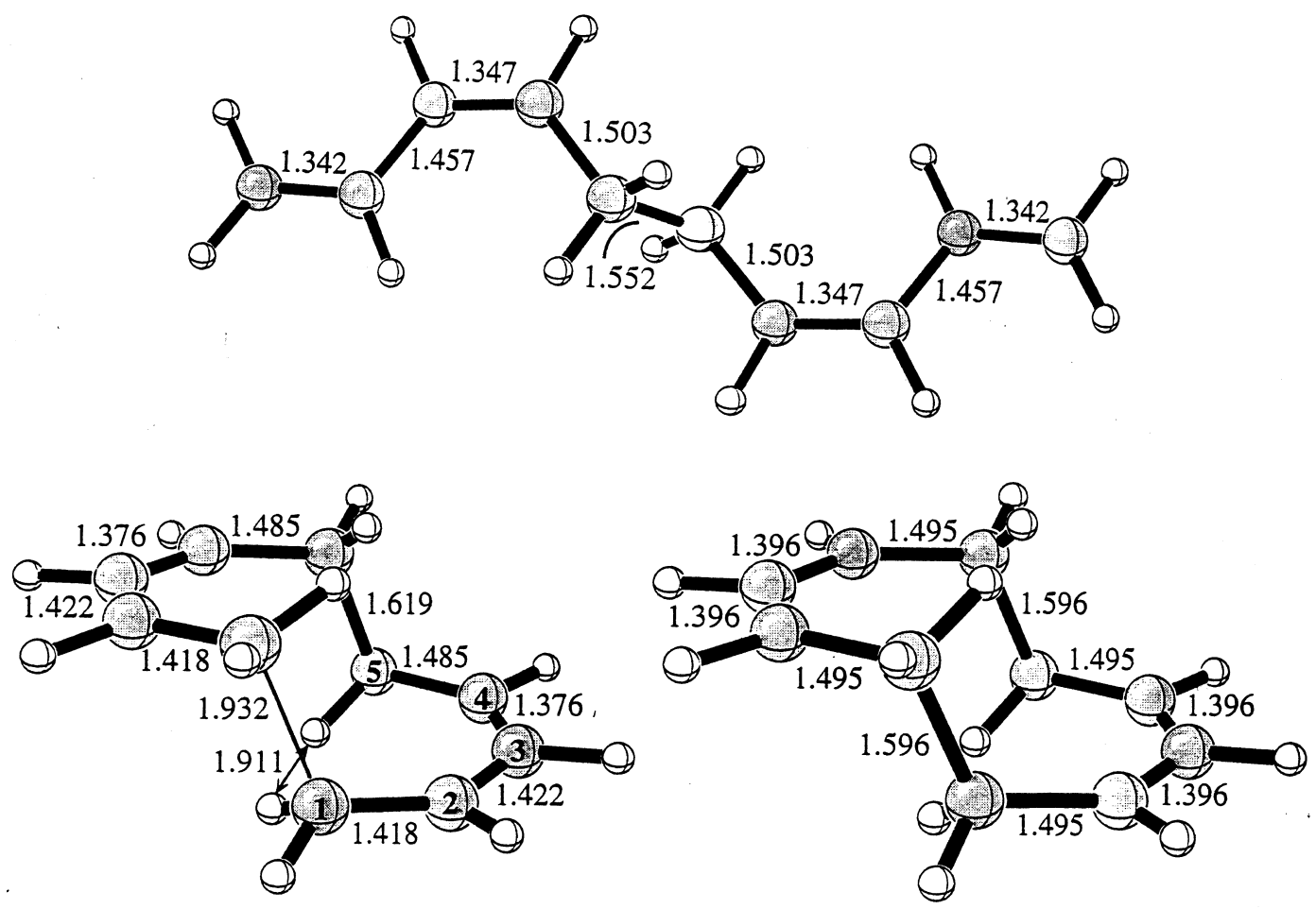

$<S^{2}>=0.26$

$$
\left\langle S^{2}>=0.92\right.
$$

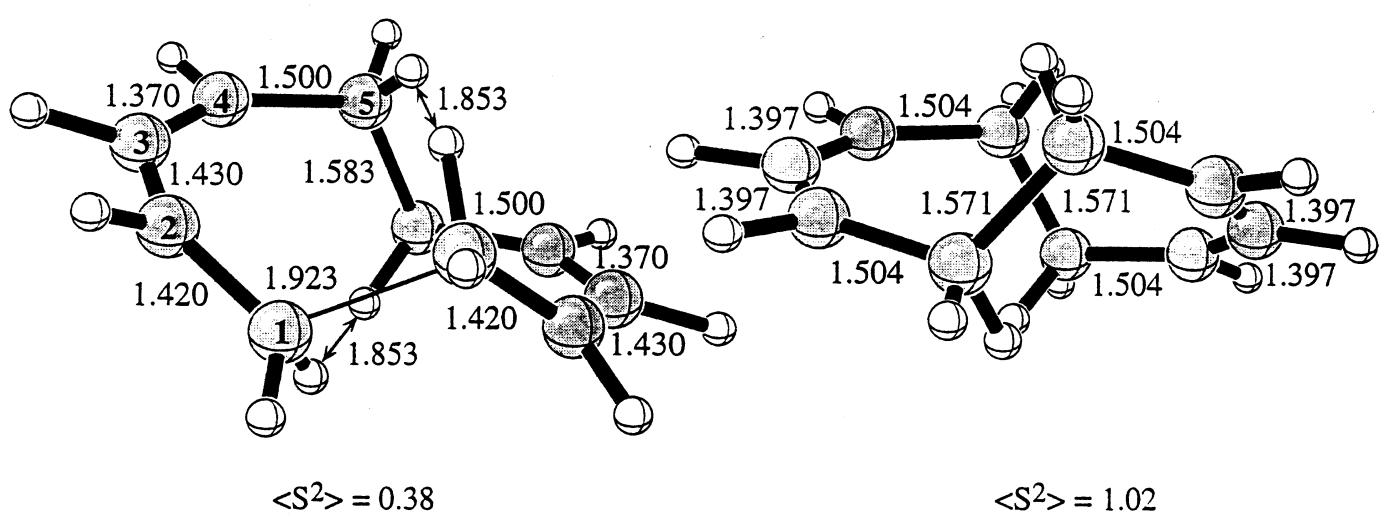

Fig. 5 B3LYP geometries of 1,3,7,9-decatetraene and the transition structures and intermediates for [5s,5s] and [5a,5a] sigmatropic shifts.

concerted cycloadditions could be aromatic [17], with $4 n+2$ cyclically delocalized electrons in a typology appropriate for aromaticity.

After several decades of debate [18], it is quite clear that the classic pericyclic reactions with six electrons involved in bonding changes-Diels-Alder, Cope, six electron electrocyclic reactions, and 1,5-sigmatropic shifts, indeed have aromatic transition states as judged by geometries [19] and magnetic properties [20]. The energies of these pericyclic reactions are also relatively favorable as compared to forbidden (antiaromatic) pericyclic processes.

As conjugated $\pi$ systems are increased in size, aromaticity eventually fades away. Thus, at about $22 \pi$ electrons and larger, $4 n+2$ systems are not specifically stabilized compared to $4 n$ systems. We have undertaken studies of pericyclic reactions involving more than six electrons. 


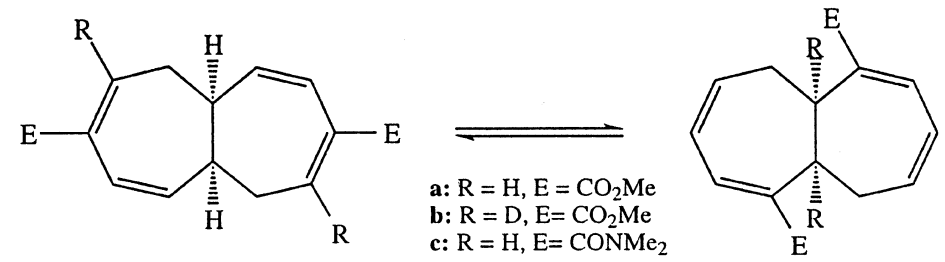

Scheme 6

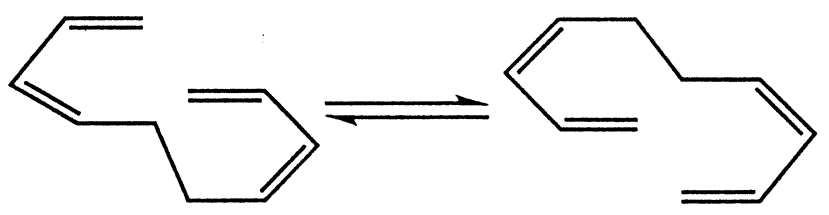

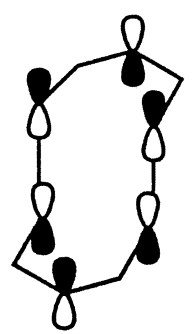

$[5 s, 5 s]$

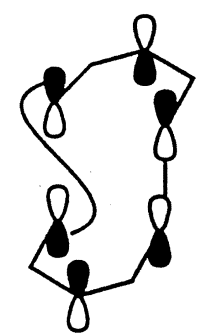

$[5 \mathrm{a}, 5 \mathrm{a}]$

\section{Scheme 7}

Computation with RHF methods predict that 5,5-sigmatropic shifts occur by concerted mechanisms involving aromatic transition states [5]. However, an accurate description of transition states requires inclusion of electron correlation, especially if the transition state has open-shell diradical character.

We explored first the 5,5-sigmatropic shift studied in tetrahydroheptalenes by Hafner and co-workers (Scheme 6), and then the [5s,5s] and [5a,5a] reactions of 1,3,7,9-decatetraene (Scheme 7). We found that the reactions are stepwise involving diradical intermediates. The transition structures and intermediates, along with 1,3,7,9-decatetraene are shown in Fig. 5. The results contrast those for the parent Cope but agree with mechanisms of 2,5-diphenyl or 2,5-divinyl hexadiene rearrangements [21].

In conclusion, we still find amazing phenomena involving simple polycyclic conjugated systems, and deviations from expectations about pericyclic mechanisms for larger systems.

\section{ACKNOWLEDGEMENTS}

We are grateful to the National Science Foundation for financial support of this research and to the Alexander von Humboldt Foundation for a Lynen Fellowship to B. G.

\section{REFERENCES}

1 M. Nendel, K. N. Houk, L. M. Tolbert, E. Vogel, H. Jiao, P. v. R. Schleyer. Angew. Chemie Int. Ed. Engl. 36, 748 (1997).

2 M. Nendel, K. N. Houk, L. M. Tolbert, E. Vogel, H. Jiao, P. V. R. Schleyer. J. Phys. Chem. A 102, 7191 (1998).

3 M. Nendel, B. Goldfuss, K. N. Houk, K. Hafner. Theochem. 461-462, 23 (1999).

4 M. Nendel, B. Goldfuss, K. N. Houk, K. Hafner. Theoretical Chemistry Accounts (1998), in press.

5 B. R. Beno, J. Fennen, K. N. Houk, K. Hafner, H.-J. Lindner. J. Am. Chem. Soc. 120, 10490 (1998).

6 P. V. R. Schleyer, P. K. Freeman, H. Jiao, B. Goldfuss. Angew. Chemie Int. Ed. Engl. 34, 337 (1995).

7 R. V. Williams, W. D. Edwards, A. Vij, R. W. Tolbert, R. H. Mitchell. J. Org. Chem. 63, 3125 (1998); Angew. Chem. Int. Ed. Engl. 36, 745 (1997), and references therein.

8 (a) K. Hafner, B. Stowasser, H.-P. Krimmer, S. Fischer, M. C. Böhm, H. J. Lindner. Angew. Chem. 98, 646 (1986); Angew. Chem. Int. Ed. Engl., 25, 620 (1986). (b) K. Hafner. Pure Appl. Chem. 54, 939 (1982).

9 J. D. Dunitz, C. Krüger, H. Irngartinger, E. F. Maverick, Y. Wang, M. Nixdorf. Angew. Chem. 100, 415 (1988); Angew. Chem. Int. Ed. Engl. 27, 387 (1988). 
10 (a) E. Heilbronner, Z. Yang. Angew. Chem. 99, 369 (1987); Angew. Chem. Int. Ed. Engl. 26, 360 (1987); E. Heilbronner. J. Chem. Educ. 66, 471 (1989). (b) R. W. Hertwig, M. C. Holthausen, W. Koch, Z. B. Maksic. Int. J. Quantum Chem. 54, 147 (1996), and references therein.

11 A. Julg, P. François. Theor. Chim. Acta 8, 249 (1967).

12 P. V. R. Schleyer, A. Dransfeld, C. Maerker, H. Jiao, N. J. R. Van E. Hommes. J. Am. Chem. Soc. 118, 6317 (1996).

13 M. J. Frisch, G. W. Trucks, H. B. Schlegel, P. M. W. Gill, B. G. Johnson, M. A. Robb, J. R. Cheeseman, T. A. Keith, G. A. Peterson, J. A. Montgomery, K. Raghavachari, M. A. Al-Laham, V. G. Zakrzewski, J. V. Ortiz, J. B. Foresman, J. Cioslowski, B. B. Stefanov, A. Nanayakkara, M. Challacombe, C. Y. Peng, P. Y. Ayala, W. Chen, M. W. Wong, J. L. Andres, E. S. Replogle, R. Gomperts, R. L. Martin, D. J. Fox, J. S. Binkley, D. J. Defrees, J. Baker, J. P. Stewart, M. Head-Gordon, C. Gonzalez, J. A. Pople. Gaussian Inc., Pittsburgh, PA (1995).

14 E. Heilbronner. Helv. Chim. Acta 751 (1965).

15 B. Freiermuth, J. Wirz. Angew. Chem. 100, 589 (1988); Angew. Chem. Int. Ed. Engl. 27, 585 (1988), and references therein; U. Griesser, PhD thesis, TUD, Darmstadt (1988).

16 The triplet state energies of benzene, naphthalene and anthracene are predicted to be $84.3,61.6$ and $41.8 \mathrm{kcal} /$ mol, respectively, above the ground state singlet by B3LYP/6-31G* calculations, whereas the experimental values are 85,61 and 42 .

17 M. J. S. Dewar, R. C. Dougherty. The PMO Theory of Organic Chemistry. Plenum Press, New York (1975).

18 K. N. Houk, J. Gonzalez, Y. Li. Accounts Chem. Research 28, 81-90 (1995).

19 K. N. Houk, Y. Li, J. D. Evanseck. Angew. Chemie 104, 711-739 (1992); Int. Ed. Engl. 31, 682 (1992).

20 P. V. R. Schleyer, H. J. Jiao. Pure Appl. Chem. 68, 209 (1996).

21 K. N. Houk, B. R. Beno, H. Y. Yoo, W. T. Borden, D. Hrovat. In preparation. 